\section{Gliomatosis cerebri in a 10-year-old male patient}

Sir,

Gliomatosis cerebri is a rare, diffuse form of glioma. The World Health Organization describes it as a diffuse glial tumor infiltrating at least two cerebral lobes, often extending to infratentorial structures and preserving the anatomic architecture. The largest series to date describing pediatric cases is the one by Armstrong et al., ${ }^{[1]}$ that included 13 patients in a 20 years-experience, though most reports include no more than 3 patients. ${ }^{[2,3]}$ We would like to describe the case of a 10-year-old male patient who presented to our institution with a 5-month history of symptoms and a relatively aggressive course.

A 10-year-old male patient was referred to our institution after a 5-month course of neuropsychiatric and neurologic symptoms consisting of behavioral changes (anhedonia, depression) and loss of strength in the right limbs and face. An magnetic resonance imaging (MRI) showed a diffuse T2-hyperintense bilateral lesion involving the cerebral hemispheres. Initially, he was treated in another hospital with pulse therapy with methylprednisolone for an acute demyelinating disease (the patient had a history of concomitant amygdalitis), but with no response.

The initial neurologic examination revealed a right supranuclear facial palsy, Grade 2 proximal and Grade 3 distal strength in the upper limbs and Grade 4 strength in the upper and lower left limbs; vivid and symmetric reflexes, Babinski sign on the right and left dysmetria. Blood and cerebrospinal fluid studies were normal. MRI showed a diffuse lesion affecting the thalamus, basal nuclei and white substance bilaterally, hyperintense in T1-weighted and T2-weighted imaging and with no contrast enhancement. Spectroscopy showed a choline peak [Figure 1].

The patient was submitted to a left parietal bur hole stereotactic biopsy, with no complications. Perioperative anatomopathological examination showed that the specimens were indeed correctly obtained. Definitive anatomopathological analysis revealed a Grade 3 astrocytoma [Figure $2 \mathrm{a}$ and $\mathrm{b}$ ] and immunohistochemistry showed positivity for glial fibrillary acidic protein and the proliferation index of $20 \%$ [Figure $2 \mathrm{c}$ and d].

The patient was started on chemotherapy with temozolomide and concomitant radiotherapy (60 Gray). A new MRI, 30 days later, showed further growth of the lesion and now contrast enhancement was noted [Figure 3]. There was a progressive neurological deterioration and parents decided to stop treatment before the end of radiotherapy.
Gliomatosis cerebri in the pediatric population remains an obscure entity, despite the growing literature in this topic. Its diffuse nature leads to a variety of presentations, making its diagnosis even more difficult. A delay in the diagnosis up to 18 months has been reported, considering one patient who presented with intention tremor; ${ }^{[1]}$ in our case, the presence of pyramidal findings prompted MRI imaging. The radiological findings were typical: A diffuse, T2-hyperintense lesion, with involvement of both cerebral hemispheres and diencephalon. ${ }^{[4]}$ Enhancement was not initially observed. Vates et al. ${ }^{[4]}$ reported $55 \%$ of contrast enhancement while other authors ${ }^{[1]}$ reported only 3 patients presenting with contrast enhancement - A characteristic that might be associated with the worst prognosis. ${ }^{[4]}$ The age of presentation appears to follow a bimodal presentation, in the second and fifth decades of life. ${ }^{[5]}$ Accordingly, the largest series presents $62 \%$ of pediatric patients older than 10 years old. ${ }^{[1]}$

Histological analysis of samples usually reveals a Grade 2 or 3 astrocytoma. Treatment remains unclear. There is a marked better survival for patients submitted to treatment. ${ }^{[1]}$ Radiotherapy is one of the most popular treatment strategies used in the literature, although concomitant chemotherapy is being increasingly used, and results show a potential increase

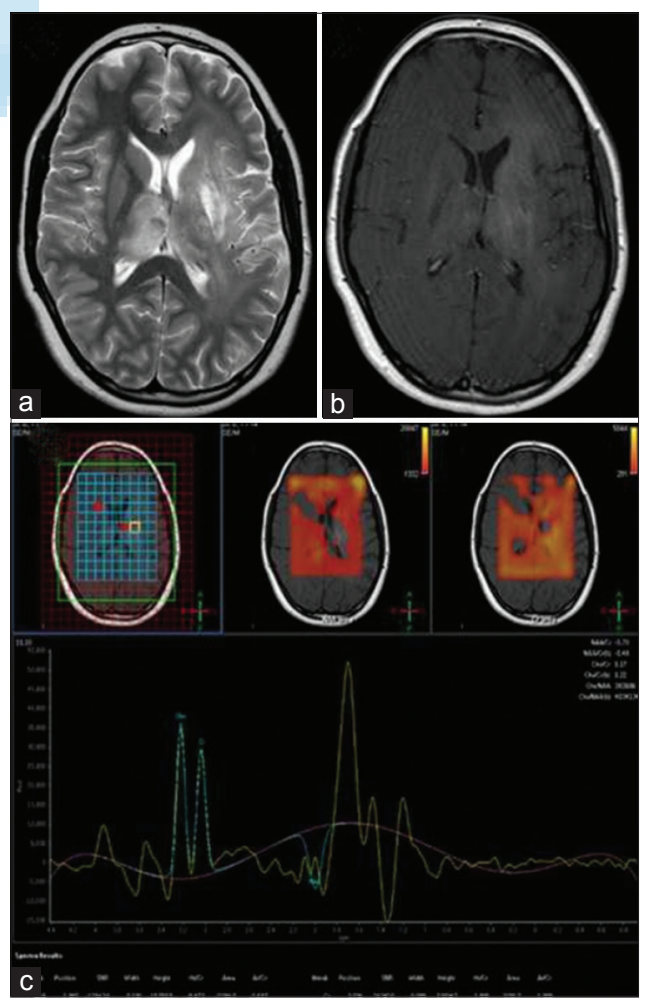

Figure 1: T2-wheighted image (a) and T1-wheighted image (b) revealing a diffuse hyperintense lesion involving the white matter and the diencephalon. Below, a spectroscopy study showing a choline peak (c) 
Letter to Editor

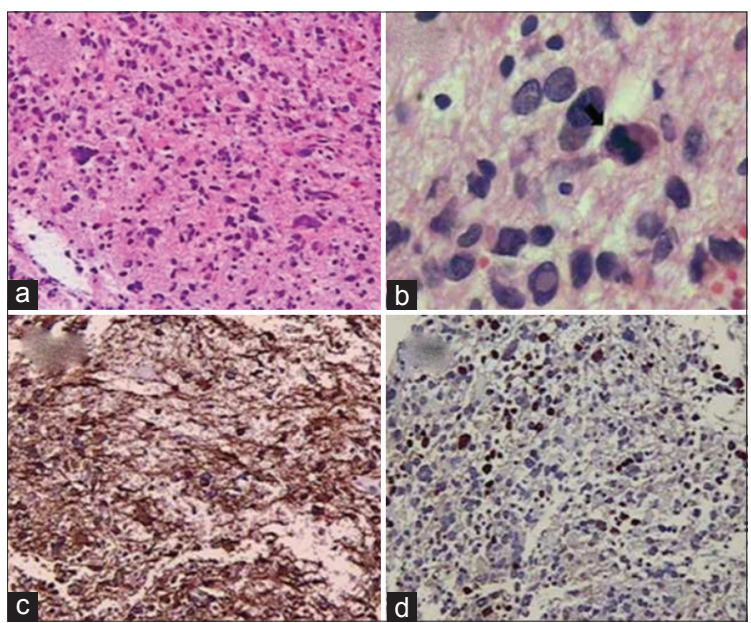

Figure 2: (a) Astrocityc cells with moderate pleomorphism and hipercellularity ( $\mathrm{H}$ and $\mathrm{E}, \times 100)$; (b) Arrow indicate mitotic figure $(\mathrm{H}$ and E, $\times 400$ ); (c) Cells demonstrate positivity for GFAP (GFAP, $\times 100)$; 2d: High proliferative index $(\mathrm{H}$ and $\mathrm{E}, \times 100)$
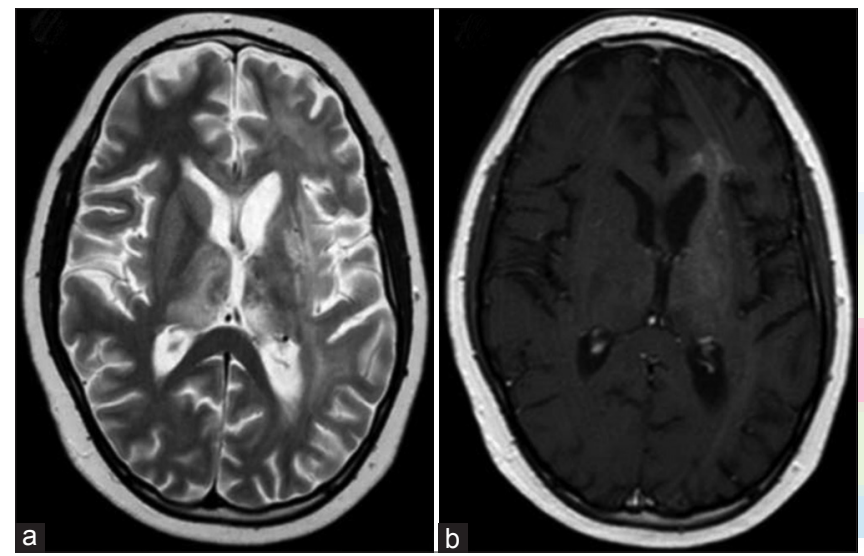

Figure 3: T2-wheighted image (a) An increase in the hyperintensities and T1-wheighted image (b) Reveals contrast enhancement

in response to treatment - especially with the advent of themozolomide. ${ }^{[3]}$

Considering only the pediatric population, the median survival is 27 months. ${ }^{[1]}$ Taking into consideration all the above, we stress the need for early diagnosis (mostly depending upon brain biopsy) in order to establish the most adequate treatment - since gliomatosis cerebri still carries a poor prognosis.

\section{Financial support and sponsorship} Nil.

\section{Conflicts of interest}

There are no conflicts of interest.

\section{Atahualpa Strapasson, Ápio Cláudio Martins Antunes, Francine Oliveira', Paulo P. Oppitz \\ Department of Neurology and Neurosurgery, Neurosurgical Unit, ${ }^{1}$ Pathology Unit, Hospital de Clínicas de Porto Alegre, Porto Alegre, Brazil \\ Address for correspondence: Ápio Cláudio Martins Antunes, MD, MSc, PhD, E-mail: apioantunes@gmail.com}

\section{$\underline{\text { References }}$}

1. Armstrong GT, Phillips PC, Rorke-Adams LB, Judkins AR, Localio AR, Fisher MJ. Gliomatosis cerebri: 20 years of experience at the Children's Hospital of Philadelphia. Cancer 2006;107:1597-606.

2. Jennings MT, Frenchman M, Shehab T, Johnson MD, Creasy J, LaPorte $\mathrm{K}$, et al. Gliomatosis cerebri presenting as intractable epilepsy during early childhood. J Child Neurol 1995;10:37-45.

3. Landi A, Piccirilli M, Mancarella C, Giangaspero F, Salvati M. Gliomatosis cerebri in young patients' report of three cases and review of the literature. Childs Nerv Syst 2011;27:19-25.

4. Vates GE, Chang S, Lamborn KR, Prados M, Berger MS. Gliomatosis cerebri: A review of 22 cases. Neurosurgery 2003;53:261-71.

5. Artigas J, Cervos-Navarro J, Iglesias JR, Ebhardt G. Gliomatosis cerebri: Clinical and histological findings. Clin Neuropathol 1985;4:135-48

This is an open access article distributed under the terms of the Creative Commons Attribution-NonCommercial-ShareAlike 3.0 License, which allows others to remix, tweak, and build upon the work non-commercially, as long as the author is credited and the new creations are licensed under the identical terms.

\begin{tabular}{|l|l|}
\hline \multicolumn{2}{|c|}{ Access this article online } \\
\hline Quick Response Code: & Website: \\
\hline & www.asianjns.org \\
\cline { 2 - 3 } & \\
\hline
\end{tabular}

How to cite this article: Strapasson A, Antunes ÁC, Oliveira F, Oppitz PP. Gliomatosis cerebri in a 10-year-old male patient. Asian J Neurosurg 2017;12:336-7. 